\title{
The competitive athlete with type 1 diabetes
}

\section{Michael C. Riddell ${ }^{1,2}$ (D) Sam N. Scott ${ }^{3,4} \cdot$ Paul A. Fournier $^{5} \cdot$ Sheri R. Colberg $^{6} \cdot$ Ian W. Gallen ${ }^{7} \cdot$ Othmar Moser $^{8}$. Christoph Stettler $^{3} \cdot$ Jane E. Yardley ${ }^{9,10,11}$ • Dessi P. Zaharieva ${ }^{12} \cdot$ Peter Adolfsson $^{13,14} \cdot$ Richard M. Bracken $^{15}$}

Received: 17 February 2020 / Accepted: 17 April 2020 / Published online: 12 June 2020

(C) The Author(s) 2020

\begin{abstract}
Regular exercise is important for health, fitness and longevity in people living with type 1 diabetes, and many individuals seek to train and compete while living with the condition. Muscle, liver and glycogen metabolism can be normal in athletes with diabetes with good overall glucose management, and exercise performance can be facilitated by modifications to insulin dose and nutrition. However, maintaining normal glucose levels during training, travel and competition can be a major challenge for athletes living with type 1 diabetes. Some athletes have low-to-moderate levels of carbohydrate intake during training and rest days but tend to benefit, from both a glucose and performance perspective, from high rates of carbohydrate feeding during longdistance events. This review highlights the unique metabolic responses to various types of exercise in athletes living with type 1 diabetes.
\end{abstract}

Keywords Athlete · Carbohydrate · Competition · Continuous glucose monitoring · Exercise · Glucose · Insulin · Nutrition · Review $\cdot$ Sport $\cdot$ Type 1 diabetes

\section{Abbreviations \\ AGP Ambulatory glucose profile \\ CGM Continuous glucose monitoring}

CSII Continuous subcutaneous insulin infusion

isCSM Intermittently scanned continuous glucose monitoring
Electronic supplementary material The online version of this article (https://doi.org/10.1007/s00125-020-05183-8) contains a slideset of the figures for download, which is available to authorised users.

Michael C. Riddell

mriddell@yorku.ca

Richard M. Bracken

r.m.bracken@swansea.ac.uk

1 School of Kinesiology and Health Science, Faculty of Health, Muscle Health Research Centre and Physical Activity \& Chronic Disease Unit, York University, 4700 Keele Street, Toronto, ON M3J 1P3, Canada

2 LMC Diabetes \& Endocrinology, Toronto, ON, Canada

3 Department of Diabetes, Endocrinology, Nutritional Medicine and Metabolism, Bern University Hospital, University of Bern, Bern, Switzerland

4 Team Novo Nordisk Professional Cycling Team, Atlanta, GA, USA

5 School of Human Sciences, Division Sport Science, Exercise and Health, University of Western Australia, Crawley, WA, Australia

6 Human Movement Sciences Department, Old Dominion University, Norfolk, VA, USA
7 Royal Berkshire NHS Foundation Trust Centre for Diabetes and Endocrinology, Royal Berkshire Hospital, Reading, UK

8 Cardiovascular Diabetology Research Group, Division of Endocrinology and Diabetology, Department of Internal Medicine, Medical University of Graz, Graz, Austria

9 Augustana Faculty, University of Alberta, Edmonton, AB, Canada

10 Alberta Diabetes Institute, Edmonton, AB, Canada

11 Women's and Children's Health Research Institute, Edmonton, AB, Canada

12 Department of Pediatrics, Stanford University School of Medicine, Stanford, CA, USA

13 Department of Pediatrics, The Hospital of Halland, Kungsbacka, Sweden

14 Institute of Clinical Sciences, Sahlgrenska Academy, University of Gothenburg, Gothenburg, Sweden

15 Applied Sport, Technology, Exercise and Medicine Research Centre (A-STEM), Swansea University, A111 Engineering East, Fabian Way, Crymlyn Burrows, Swansea SA1 8EN, UK 
MDI Multiple daily injections

rtCGM Real-time continuous glucose monitoring

TIR Time in range

\section{Introduction}

As we approach the 100-year mark of the discovery of insulin, people with type 1 diabetes may achieve a near normal life expectancy with an overall high quality of life, but this requires tight maintenance of on-target blood glucose levels and good cardiovascular health [1]. Both of these aspects of diabetes management are still very challenging for individuals with type 1 diabetes, even with access to specialised diabetes care [2]. Being regularly active with the disease improves cardiometabolic health [3] and is associated with increased longevity [4].

Leading up to the next Summer Olympic Games, numerous athletes with type 1 diabetes will train and compete at the elite level, with some aspiring to pursue their podium dreams. The day-to-day management of the condition remains onerous, however, given the monotonous tasks of monitoring glucose, carbohydrate/macronutrient counting, insulin dosing, and managing stress/sick days, particularly while training and preparing for competition (Fig. 1). Ongoing research is increasingly focusing on the unique physiology of such high-level athletes with type 1 diabetes, while also investigating how new insulin analogues and other therapeutic agents/ technologies might improve their glycaemic management. This review highlights the challenges of high-level training and competition in athletes with type 1 diabetes and identifies some of the knowledge gaps that limit our capacity to provide evidence-based strategies to optimise their performance.

\section{Energy metabolism}

Physical activity at all levels requires the mobilisation of various fuel sources. To help better understand the unique responses to exercise in type 1 diabetes, we briefly describe the main energy systems used during various forms of exercise in the following sections. Possible alterations in energy metabolism caused by the disease are highlighted.

ATP and phosphocreatine During skeletal muscle contraction, energy is provided from ATP, which is immediately resynthesised from phosphocreatine. The limited phosphocreatine stores require that ATP resynthesis occurs by catabolising other fuel sources (lipid and carbohydrates) for exercise events lasting more than a few seconds (Fig. 2). With insulin therapy, and in the absence of nephropathy, ATP and phosphocreatine levels at rest and post exercise appear normal in individuals with type 1 diabetes [5]. However, a slower phosphocreatine recovery time and impaired mitochondrial function/capacity may exist in some individuals with the disease in whom blood glucose levels are not tightly managed with insulin therapy [5, 6]. Insulin deprivation and/or sustained hyperglycaemia can impair mitochondrial function, promote mitophagy, lower ATP provision and increase reactive oxygen species production in muscle, heart, kidney and brain [7].

Carbohydrates During high-intensity exercise, carbohydrate is a primary fuel source. Glucose stores within liver and skeletal muscle, in the form of glycogen, depend on the size and training status of the individual and are the body's primary carbohydrate stores. In the average adult male weighing $70 \mathrm{~kg}$, up to $160 \mathrm{~g}$ of glucose can be stored in the liver, while up to $700 \mathrm{~g}$ of glucose can be stored in the muscle [8]. A 'normal' blood glucose concentration of $\sim 5-7 \mathrm{mmol} / \mathrm{l}$ amounts to only $\sim 4-6 \mathrm{~g}$ of total blood glucose, depending on the person's size. In individuals without diabetes, intense exercise causes a transient rise in glucose by $\sim 2 \mathrm{mmol} / \mathrm{l}$ [9], while prolonged moderate-intensity exercise induces a small and transient drop in glucose by $\sim 2$ $\mathrm{mmol} / 1$ [10], albeit responses are highly variable. Glucose production, predominantly by the liver via glycogenolysis and gluconeogenesis, as well as oral carbohydrates, help support normal blood glucose levels [11] (Fig. 2). Individuals with type 1 diabetes can have normal levels of muscle and liver glycogen content if they are adequately fed, take insulin and have good glycaemic control $\left(\mathrm{HbA}_{1 \mathrm{c}}<58 \mathrm{mmol} / \mathrm{mol}[7.5 \%]\right)[12,13]$. Hepatic glycogen levels are lowered by poor glycaemic control in individuals with type 1 diabetes [14], with only a partial restoration with short-term improvements in glycaemic control [15].

The flux of glucose from liver to muscle during exercise is impacted by insulin treatment, which can result in either hypoor hyperglycaemia [16]. High insulin levels limit hepatic glucose mobilisation and increase muscle glucose disposal, thereby causing hypoglycaemia. Inadequate insulin levels cause hyperglycaemia, as glucose production exceeds utilisation [16].

Lipids Adipose tissue and skeletal muscle lipid stores are plentiful, even in lean individuals. Lipids are used heavily during prolonged exercise, particularly as the activity duration increases (Fig. 2). Peak absolute lipid oxidation rates occur at $\sim 55-60 \%$ of maximal aerobic rate in trained individuals [17]. Intensive insulin therapy in type 1 diabetes often increases body fat stores and body weight [18], although this effect can be attenuated with dietary restriction [19] and/or endurance training [20]. Lipolytic potential may be elevated in type 1 diabetes, perhaps because of increased $\beta$ adrenoceptors on fat cells [21]. However, a high insulin level during exercise suppresses lipolysis/fat oxidation, as compared with basal insulin concentrations [22] (see below).

Protein Although protein is a major component of lean tissue, it does not normally contribute significantly to energy 
a
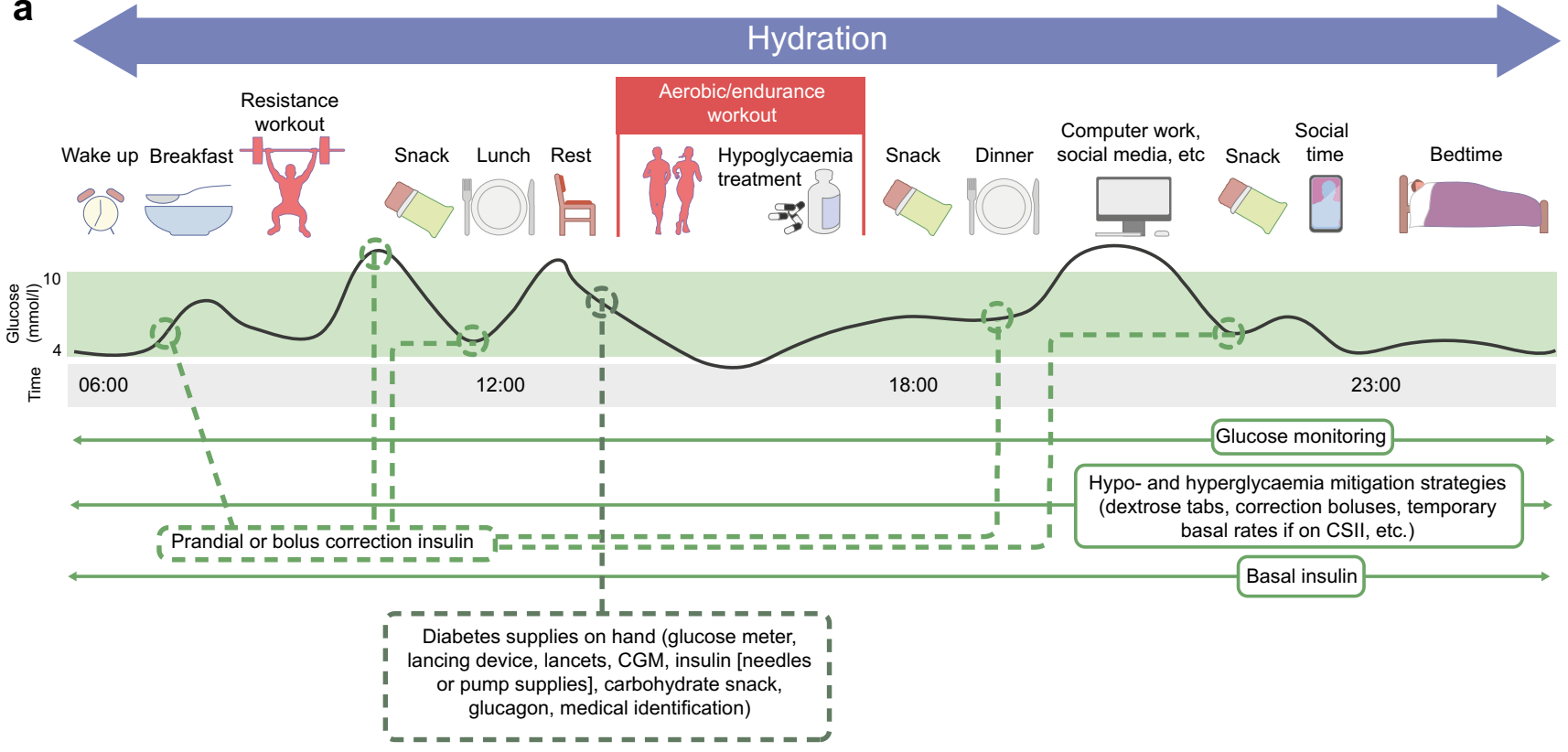

b
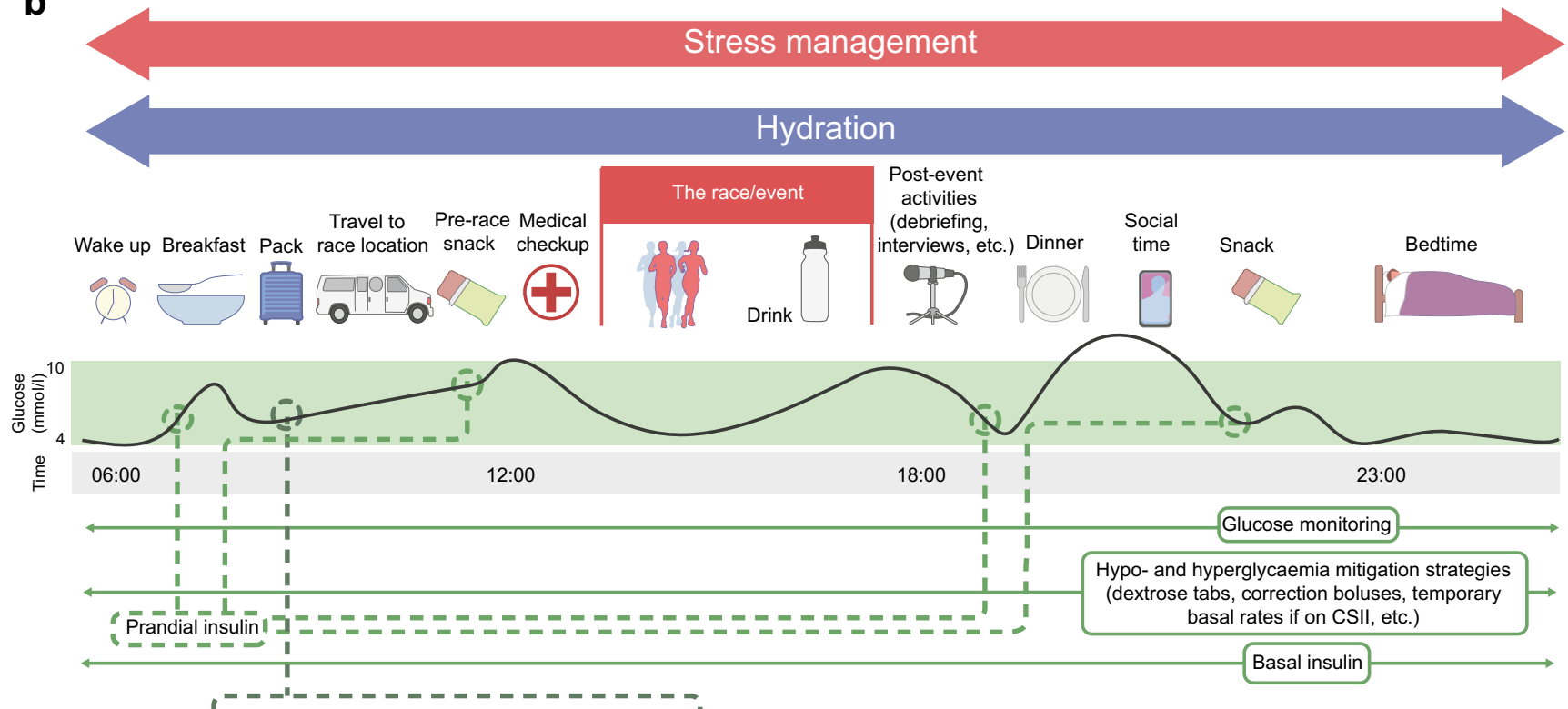

Diabetes supplies (syringes, insulin, glucagon,

rtCGM/isCGM supplies, glucose meter, ketone meter

pump etc, spare supplies, carbohydrate snacks, etc.)

pump etc, spare supplies, carbohydrate snacks, etc.)

Fig. 1 Example training day (a) and competition day (b) for a competitive athlete with type 1 diabetes. A number of variables need to be considered and controlled by an athlete with type 1 diabetes, including glucose monitoring, basal and bolus insulin-dose modifications, snacks and meals, hypo- and hyperglycaemia mitigation, hydration and stress management. Although some flexibility may be allowed on training days

metabolism. However, some protein-derived amino acids, such as leucine or alanine, can contribute minimally to skeletal muscle energy needs, especially when carbohydrate availability is restricted (i.e. by low-carbohydrate diets, periods of insulin deficiency) [23]. The gluconeogenic conversion of with regard to the timing of training and meals, this flexibility is lost on competition days due to strict competition schedules. Note that this is an example and will differ depending on numerous factors such as the event that the athlete competes in. This figure is available as part of a downloadable slideset

protein-derived and free amino acids into glucose during exercise is upregulated in type 1 diabetes if insulin is withheld [24]. Insulin deficiency for as little as $8 \mathrm{~h}$ in type 1 diabetes, perhaps in combination with other factors (hyperglycaemia, elevated cortisol, inflammation, etc.), rapidly promotes 
Fig. 2 Energy substrates for exercise. The source of energy substrates during exercise varies depending on exercise duration. During skeletal muscle contraction, in the first few seconds of exercise, energy is provided from ATP, which is immediately resynthesised from phosphocreatine (PC). For exercise of longer duration, ATP resynthesis occurs by catabolising other fuel sources (lipids and carbohydrates). Figure based on previously published data $[102$, 103]. This figure is available as part of a downloadable slideset

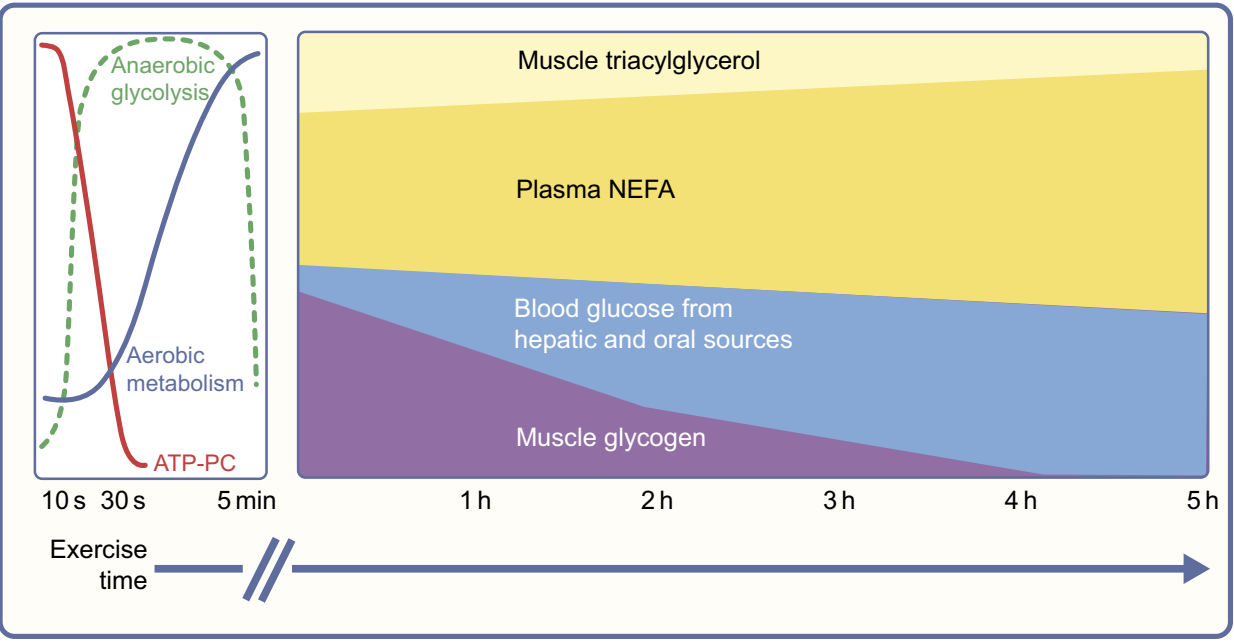

protein catabolism, likely via activation of muscle-specific transcription factors [25].

\section{Insulin regulation and dysregulation during exercise}

Insulin mediates glucose disposal into skeletal muscle and adipose tissue via increased glucose transporter type 4 translocation. In liver, insulin signalling supresses glucose production and activates glycogen synthesis via activation of various enzymes, including glucokinase and glycogen synthase [26]. During endurance exercise in individuals without diabetes, insulin secretion decreases via increased sympathoadrenal drive, with the magnitude of decline closely linked to activity intensity and duration [27]. This drop in insulin secretion facilitates lipid and glucose mobilisation from stores outside of the muscle, while minimising the risk for hypoglycaemia as contraction-mediated glucose disposal increases [16]. With brief intensive exercise bouts, insulin secretion increases during early recovery to offset rising glucose concentrations [9].

In individuals with type 1 diabetes, circulating insulin levels depend on the amount and location of insulin administration. Because insulin levels cannot immediately be lowered at exercise onset, individuals with type 1 diabetes are often hyperinsulinaemic during their activity (Fig. 3). The relative hyperinsulinaemia during prolonged moderate-intensity exercise supresses lipolysis/fat oxidation [22] while increasing whole-body glucose utilisation and hypoglycaemia risk [16]. Exercise increases absorption rates of some [28], but not all [29] forms of insulin, which can exacerbate the risk for hypoglycaemia. With intensive exercise, hyperglycaemia post exercise is aggravated by the inability to automatically increase insulin delivery into the portal circulation [9]. Omitting insulin altogether, well in advance of exercise, promotes excessive hyperglycaemia and ketone production [30].

\section{Selecting an insulin delivery method}

The primary goal of exercise management in athletes with type 1 diabetes should be to limit dysglycaemia, with a secondary goal of attempting to replace insulin to healthy physiological insulin levels. Complete restoration of insulin to physiological levels is impossible since insulin is administered subcutaneously rather than released into the portal circulation. While some athletes with type 1 diabetes perform well using multiple daily injections (MDI) of insulin [31], others prefer the flexibility afforded by continuous subcutaneous insulin infusion (CSII) [32]. The latter allows for temporary basal rate reductions in anticipation of and/or recovery from prolonged aerobic exercise, temporary basal rate increases for very intensive aerobic/ anaerobic work, and for basal rate reductions overnight, if nocturnal hypoglycaemia is an issue. Hybrid closed-loop technology may support glycaemic management in athletes better than traditional pump therapy as insulin delivery is informed by current glucose levels, glucose predictions, previous insulin delivery and other features of proprietary algorithms that improve overall 'time in range' (TIR; the percentage of time that an individual's blood glucose is within the target level) [33]. Currently approved hybrid closed-loop devices are suitable for prolonged aerobic exercise if a temporary (higher) glucose target is set well before the start of exercise (i.e. 45$90 \mathrm{~min}$ before the exercise start time).

In spite of these benefits, many individuals report that CSII interferes with their sporting activities or that they would rather not be attached to a medical device [34]. Maintaining insulin infusion sets and glucose monitoring devices during exercise and sport is challenging when there is increased perspiration and the potential for sport contact and/or friction. For athletes who prefer pump removal during exercise, a hybrid approach that combines basal insulin delivery split between an ultra-longacting insulin and $50 \%$ reduced basal insulin delivery by CSII [35] can be used. The addition of continuous glucose monitoring (CGM) is beneficial, as athletes (particularly those with 


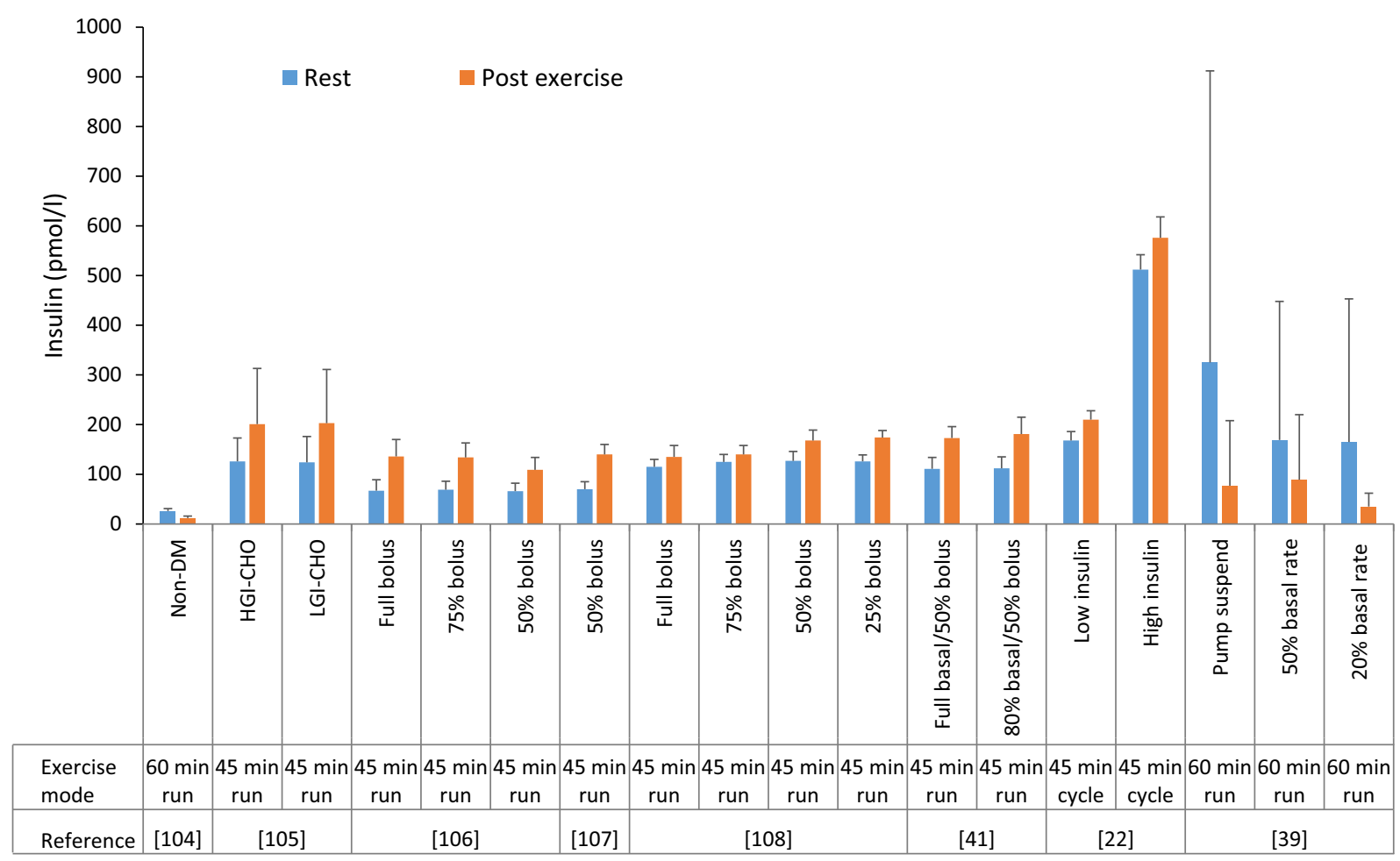

Fig. 3 Circulating insulin levels in physically active individuals with type 1 diabetes. The values shown represent the insulin concentration as measured before (rest) and soon after the end of exercise in a variety of previously published studies, which included various cohorts/conditions: non-diabetic control participants (Non-DM); participants with type 1 diabetes who underwent high- (HGI-CHO) or low- (LGI-CHO) carbohydrate feeding interventions; participants with type 1 diabetes who underwent bolus insulin-dose reductions (full bolus; $75 \%$ bolus; $50 \%$ bolus; $25 \%$ bolus); participants with type 1 diabetes who underwent basal

hypoglycaemia unawareness [36]) can gather glucose data, respond to glucose trend arrows and alerts/alarms, and optimise therapy [37]. Real-time CGM (rtCGM) offers the advantage of alerts and alarms when glucose drifts away from target; however, exercise itself has an impact on sensor accuracy [38].

\section{Strategies to address relative hyperinsulinaemia during prolonged exercise}

Relative hyperinsulinaemia during prolonged aerobic exercise can be offset by basal and/or prandial insulin-dose reductions and/or by increased carbohydrate feeding. For those using CSII, basal insulin delivery can be reduced by $50-80 \%$ $90 \mathrm{~min}$ before exercise [39]. Suspending insulin delivery at exercise onset is safe, albeit less effective in mitigating the drop in blood glucose level [40]. Basal insulin delivery can be resumed immediately post exercise, allowing circulating insulin levels to rise before the recovery meal.

For individuals using MDI, the basal insulin dose can be reduced by $20-50 \%$ before exercise to mitigate hypoglycaemia risk [41]. Even insulin degludec can be reduced by $\sim 25 \%$, but this reduction should be initiated 3 days before the exercise insulin-dose reductions, along with bolus dose reductions for MDI (full basal $/ 50 \%$ bolus; $80 \%$ basal $/ 50 \%$ bolus); participants with type 1 diabetes who had low $\left(15 \mathrm{mU} \mathrm{m}^{-2} \mathrm{~min}^{-1}\right)$ or high $\left(50 \mathrm{mU} \mathrm{m}^{-2} \mathrm{~min}^{-1}\right)$ intravenous insulin infusions; and type 1 diabetic participants who underwent basal insulin rate reductions for CSII (pump suspend; $50 \%$ basal rate; $20 \%$ basal rate). The mode of exercise and duration of activity is shown on the $x$-axis. Data are from select studies [22, 39, 41, 104-108] and were analysed by R. M. Bracken. This figure is available as part of a downloadable slideset

event [42]. For other long-acting basal insulins (e.g. insulin glargine, insulin detemir), the total basal insulin dose can be divided into a morning and evening dose to allow for more flexible adjustments. As an alternative (or complement) to basal insulin-dose reduction, simple carbohydrate consumption (up to $70-90 \mathrm{~g} / \mathrm{h}$ ) during prolonged aerobic activities can help prevent hypoglycaemia and support performance [43].

In addition to the inability to lower insulin secretion into the portal circulation at exercise onset, glucagon fails to rise normally during prolonged exercise in type 1 diabetes, predisposing athletes to developing hypoglycaemia during some activities [44]. Administering a mini dose of glucagon [45] or glucagon in a dual-hormone closed-loop pump [46] helps to eliminate hypoglycaemia; however, this has never been tested in a setting of competition.

\section{Strategies to address relative hypoinsulinaemia post exercise}

Managing competition-related hyperglycaemia, particularly at the start of an event, can be challenging [47]. Psychological strategies, such as cognitive restructuring and overlearning of skills, 
may help offset the stress effects [48]. Some athletes will tolerate, or even plan for, a slightly elevated blood glucose level when starting an event; others may choose to use a temporary basal rate increase (if using CSII), a partial bolus insulin correction or a prolonged aerobic warm-up to correct hyperglycaemia. Giving a standard (i.e. full) insulin bolus correction before a prolonged aerobic exercise event is not recommended unless ketones are elevated, since doing so increases hypoglycaemia risk [11].

Many athletes have difficulty managing immediate postevent hyperglycaemia [42]. When fasted, a bolus insulin correction can be given after intense aerobic exercise [49] or after resistance exercise [50]. However, with most prolonged exercise events, late-onset hypoglycaemia remains common for athletes [51] and, thus, basal insulin-dose reduction and/or bedtime snack strategies are recommended [16].

\section{Planning for glucose management with dynamic training protocols}

Athletes partake in varied training regimens, often differing daily or seasonally with regard to training mode, intensity and duration. Professional athletes frequently use 'polarised' training strategies, starting early in the season with low-intensity, high-volume work, followed by high-intensity, lower volume work later in the season. Before competition, training volume generally tapers. Such training varieties may make glucose management challenging for athletes with type 1 diabetes. However, by individualising standard recommendations, athletes can personalise strategies through trial and error to temper glycaemic excursions [47].

Even when athletes with type 1 diabetes have well-honed strategies, it is often useful to work with endocrinologists and other healthcare providers [47]. The clinical team should first review the ambulatory glucose profile (AGP) if rt-CGM or intermittently scanned CGM (isCGM) is used, along with the athlete's current strategies for glucose management around training and competition. Clinicians should review glucose monitoring downloads to ensure adequate basal insulin dosing and correct bolus insulin usage to cover meals and hyperglycaemic excursions [52]. The clinical team should offer reasonable initial strategies for athletes who are newly diagnosed with type 1 diabetes, such as the use of self-monitoring of blood glucose, nutrition counselling, newer insulin analogues and CSII with rtCGM or isCGM, as appropriate. Various features, such as cost, comfort and accuracy, are considerations for product choice.

\section{Strategies to manage different modalities and durations of exercise}

Assuming that glycaemic management has been optimised for non-exercise days, the exercise type (aerobic, anaerobic, mixed) and duration will largely dictate the strategies employed for active days [16]. In general, prolonged predominantly aerobic exercise promotes a drop in blood glucose concentration, while more intensive aerobic and anaerobic events promote a glucose rise [16]. The rise in blood glucose during intensive exercise in the fasted state is reproducible and tends to be associated with a rise in lactate [53]. For endurance events, such as marathons and road cycling, athletes often have elevated glucose levels prior to the event, sometimes because of psycho-physiological stress responses [54] or as a purposeful coping strategy to limit the likelihood of developing hypoglycaemia during the event [55]. Typically, carbohydrate consumption is needed to maintain performance and prevent hypoglycaemia in endurance events lasting $\geq 60$ min [16]. More aerobically fit individuals may have higher hypoglycaemic risk during exercise than those who are less fit [56], potentially due to higher absolute power outputs and greater rates of carbohydrate oxidation. Conversely, having insulin at near basal levels or lower typically causes a rise in glucose during burst events, like pole vaulting, power lifting, sprinting or wrestling [57].

\section{Optimising performance with nutrition}

Several evidence-informed nutritional strategies exist to support athletes in various settings [58]. However, for athletes with type 1 diabetes, it is unclear if special or additional considerations are required to optimise performance. Like athletes without diabetes, those with diabetes follow the full spectrum of carbohydrate intake strategies, depending on their activity and training regimens.

Carbohydrate intake While some athletes use carbohydrate counting to determine meal- and snack-based insulin-dose adjustments, this procedure often lacks precision, particularly with high-carbohydrate feeding [59]. Moreover, carbohydrates with differing glycaemic indices and mixed meals make this practice difficult. If exercise occurs soon after a meal, glucose disposal from the meal may be stimulated by both insulin-dependent and insulin-independent signalling [60]. Although high-glycaemic index meals/snacks generally increase insulin resistance in people without diabetes [61], carbohydrate loading pre exercise and/or carbohydrate feeding during competition with simple sugars is feasible [43] and likely to be important for performance and glycaemic management during competition and training.

According to self-report, some athletes with type 1 diabetes adopt low or moderate carbohydrate diets to improve glycaemic management (Fig. 4a). It is currently unclear if this dietary approach has an impact on performance. Good longterm glucose management improves performance in athletes with type 1 diabetes: those with lower $\mathrm{HbA}_{1 \mathrm{c}}$ levels ( $\sim 88 \mathrm{mmol} / \mathrm{mol}[6.5 \%])$ have superior cardiorespiratory 

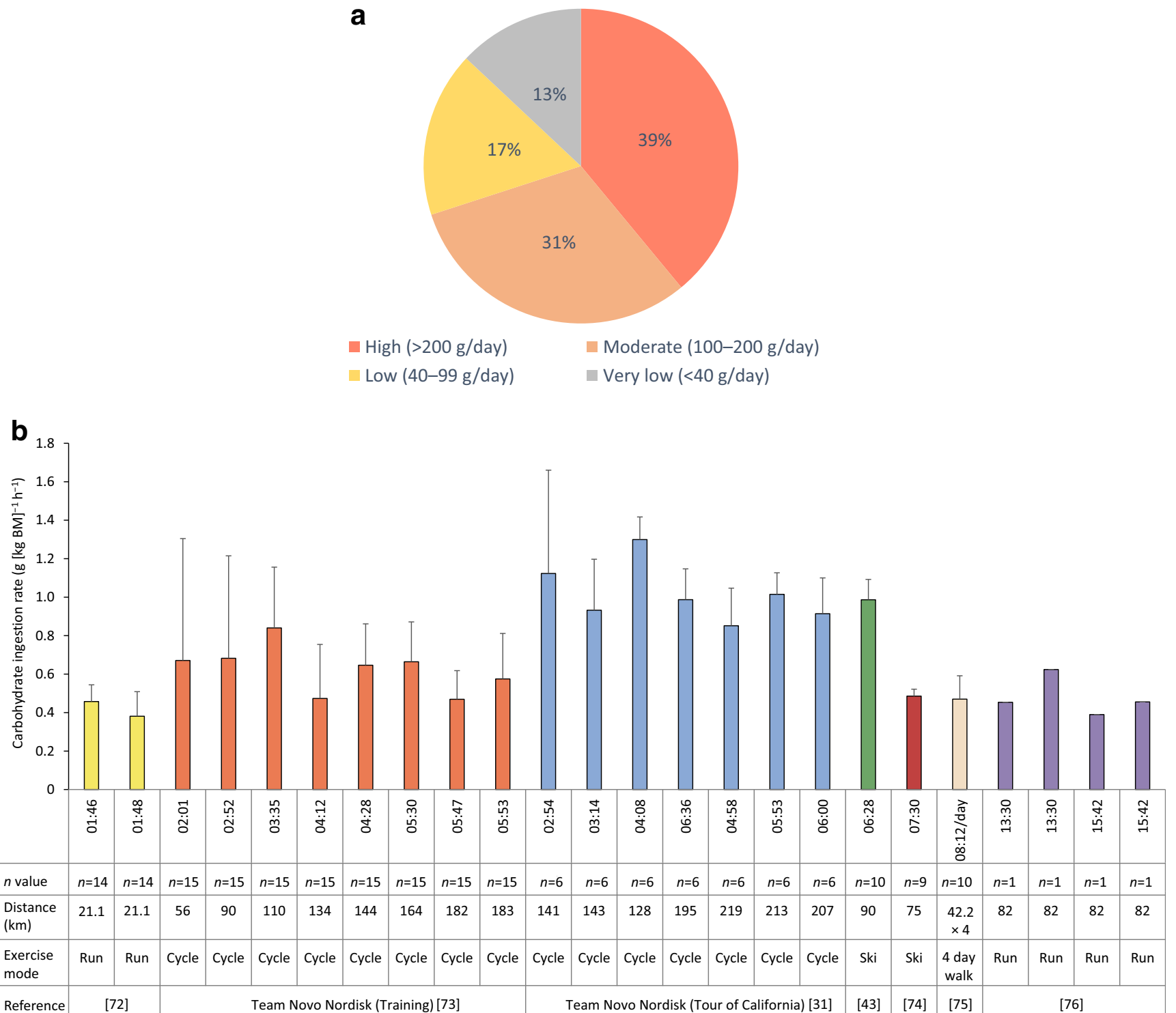

Fig. 4 Carbohydrate intake patterns in athletic individuals with type 1 diabetes. (a) Daily macronutrient intake from carbohydrates in 252 active adults with type 1 diabetes and of varying athletic level who were surveyed about their carbohydrate intake patterns. Approximately $40 \%$ self-reported carbohydrate consumption within the current acceptable macronutrient distribution range of 45-65\% of energy intake (>200 g/ day) [109], whereas $\sim 30 \%$ consciously moderated their carbohydrate intake (100-200 g/day), typically by avoiding starchy or sugary foods. The remainder described following either a low-carbohydrate diet $(17 \%$ of participants; $40-99 \mathrm{~g} /$ day) or a very-low-carbohydrate diet (13\% of

fitness and pulmonary function than those with higher $\mathrm{HbA}_{1 \mathrm{c}}$ levels ( $\sim 62 \mathrm{mmol} / \mathrm{mol}$ [7.8\%]) [62]. However, it is unclear if achieving this via restricted carbohydrate feeding, rather than by administering more insulin or by some other means, may compromise endurance performance and/or increase hypoglycaemia or ketoacidosis risk [63].

Muscle glycogen replenishment following exercise requires effective blood glucose management and balancing of carbohydrate intake with insulin dosing. In one study, participants), with a meal plan of carbohydrate intake of $<40 \mathrm{~g} /$ day (S. R. Colberg, unpublished data). (b) Carbohydrate intake rates during endurance training and competition events: Data are from select studies and were analysed by R. M. Bracken [31, 43, 72-76]. The $x$-axis provides information on exercise duration (h:min) and also profiles the exercise distance and mode used in each of the published studies. Mean carbohydrate intake rate across the studies analysed was $0.70 \pm 0.26 \mathrm{~g}$ [kg body mass $]^{-1} \mathrm{~h}^{-1}(50 \pm 18 \mathrm{~g} / \mathrm{h})$. BM, body mass. This figure is available as part of a downloadable slideset

moderate carbohydrate intake ( $50 \%$ of total energy) was superior to high carbohydrate intake (59\% of total energy) for glycogen replenishment, glycaemic management and performance [64]. If carbohydrate intake is limited after prolonged exercise, restoring muscle glycogen levels is likely to take longer [65], which may increase nocturnal hypoglycaemia risk [63]. Co-ingesting protein with moderate amounts of carbohydrate (e.g. $0.8 \mathrm{~g} \mathrm{~kg}^{-1} \mathrm{~h}^{-1}$ ) post exercise may provide a feasible option for normal muscle glycogen repletion, while 
still balancing blood glucose levels [66]. However, high dietary protein intake does not appear to increase muscle glycogen repletion rates further in those already consuming enough carbohydrate [67].

During exercise, carbohydrate requirements depend on the use of insulin or other medications, exercise timing, activity undertaken and starting blood glucose levels. Because of a tendency for lower insulin levels and/or elevation in morning cortisol and growth hormone levels, training before breakfast may require little-to-no carbohydrate ingestion during activity, as compared with afternoon exercise [68]. An elevated preexercise blood glucose level in the morning or afternoon reduces carbohydrate intake needs. Participation in resistance exercise [69] and high-intensity interval-type training [53] may not require carbohydrate intake since glucose levels tend not to drop.

Carbohydrate intake and/or insulin reduction is typically required for activities lasting $>30 \mathrm{~min}$ in a non-fasting state, to prevent hypoglycaemia. For low-to-moderate-intensity aerobic activities lasting 30-60 min that are undertaken when circulating insulin is at basal levels, the intake of small amounts $(8-20 \mathrm{~g})$ of carbohydrate may suffice to limit hypoglycaemia, but are not likely to affect performance [70]. With higher circulating insulin exposure due to bolus insulin administration, $30-60 \mathrm{~g} / \mathrm{h}$ carbohydrate may be needed when the exercise duration lasts $>30 \mathrm{~min}$ [71]. Carbohydrate intake rates of $0.4 \mathrm{~g}$ to $1.3 \mathrm{~g}$ carbohydrate per $\mathrm{kg}$ body mass per $\mathrm{h}$ have been reported for athletes with type 1 diabetes exercising in performance settings lasting $\geq 60 \mathrm{~min}$ (Fig. $4 \mathrm{~b}$ ). These studies found that carbohydrate intake within this range prevented hypoglycaemia and enhanced endurance performance in prolonged exercise [31, 43, 72-76].

Hydration and electrolyte balance Adequate hydration during training and competition is required to maintain blood volume and for thermoregulation [77]. Athletes with type 1 diabetes may experience mild to moderate dehydration during exercise if their blood glucose is elevated, which can be exacerbated by the fact that hyperglycaemia increases urinary water loss. Fluid intake during training tends to be higher in type 1 diabetes, as compared with control individuals, perhaps because of elevated thirst caused by hyperglycaemia [78]. In general, plain water or a carbohydrate-electrolyte beverage, depending on glucose level, should be consumed at a rate of $\sim 11 / \mathrm{h}$ [79].

\section{Recommendations for rtCGM/isCGM use}

rtCGM and isCGM may allow athletes with type 1 diabetes to better manage their glucose levels during training, competition and recovery. When used during prolonged exercise, the initiation of carbohydrate feeding can be based on glucose concentrations (e.g. sensor glucose $<8.0 \mathrm{mmol} / \mathrm{l}$ ), glucose trend arrows and rate of change data [70]. Glucose data should be analysed together with a connected smart pen that can automatically log insulin administration [80], or with pump data [81], to better manage complex situations that may arise due to exercise. With multi-day training, monitoring the AGP can help athletes and clinicians to define achievable blood glucose (and, consequently, performance) goals [82]. Due to the unique challenges of glycaemic management during competition, athletes with type 1 diabetes should engage in several training sessions that closely mimic competition-day conditions to optimise management strategies.

The glycaemic targets for health and performance of athletes with type 1 diabetes should be individualised. However, we propose that for any training period, athletes should aim for $>70 \%$ TIR $(3.9-10.0 \mathrm{mmol} / \mathrm{l})$, with $<4 \%$ below $3.9 \mathrm{mmol} / \mathrm{l}$ and $<1 \%$ below $3.0 \mathrm{mmol} / \mathrm{l}$, identical to the recommendations for the type 1 diabetes adult population [83] (Fig. 5). Since hypoglycaemia during exercise can severely impact performance and, potentially, heart rate variability [84], athletes should aim for $<1 \%$ time below target and $>75 \%$ TIR during competition. Reducing glycaemic variability, as measured by a coefficient of variation of $\leq 36 \%$ for CGM values, is also recommended since values above this threshold appear to correlate with increased hypoglycaemia risk [85]. While we acknowledge that these targets are ambitious, they may be achievable with newer technologies and dedication.

\section{Additional considerations}

Many competing athletes deal with additional factors that can affect performance. Poor recognition of hypoglycaemia, travelling, optimisation of body weight and/or menstrual cycle variations in insulin sensitivity are a few factors that may have an impact on glucose control and performance.

Hypoglycaemia unawareness Individuals with type 1 diabetes often develop impaired awareness of hypoglycaemia, which increases the risk for a severe hypoglycaemic event by approximately sixfold [86]. Active individuals may be at an elevated risk for developing impaired hypoglycaemia awareness and counterregulatory failure during exercise: routine exercise blunts counterregulation during a hypoglycaemic event [87], which may be a form of habituation. Altering the training exposure to a novel stimulus, such as high-intensity interval training, may help dishabituation and may improve both hypoglycaemia symptom recognition and counterregulation [88].

Weight management Sports like gymnastics and cycling require low body weight (and/or fat mass) for performance, while others benefit from maximised body mass (e.g. Olympic deadlifts). Combat athletes aiming to compete in the lightest 


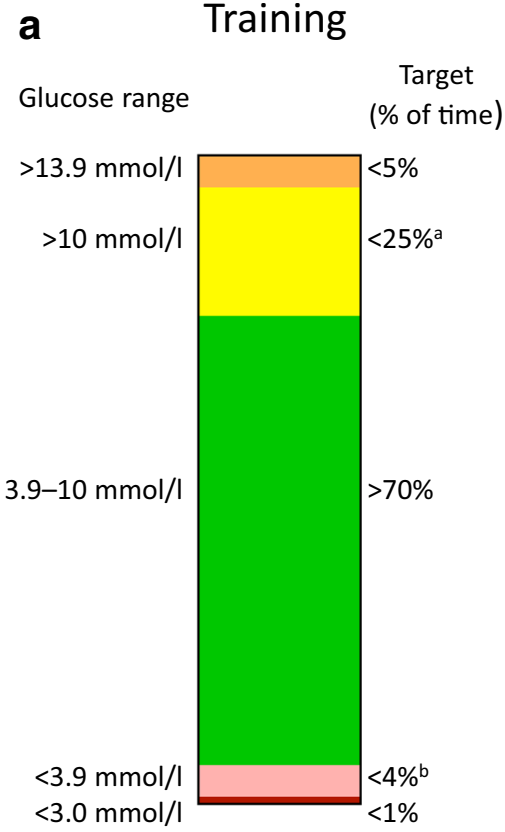

Fig. 5 Proposed CGM-based targets for athletes with type 1 diabetes during training (a) and competition (b). Targets for training days are based on the international consensus [83], while the targets for competition are based on the opinion of the authors. Individual targets should be set by the individual's healthcare provider with consideration of several variables, including age, duration of diabetes, diabetes-related complications and level of hypoglycaemia awareness. In both training and

weight category possible often must lose weight for pre-event weigh-ins [89]. These athletes typically combine chronic and acute strategies to achieve target weights, including energy restriction and dehydration [90]. Such high-risk practices may increase the likelihood of severe dehydration and, possibly, even death [91]. Safe and effective weight management strategies are possible in athletes with type 1 diabetes. Since insulin is an anabolic/anti-catabolic hormone [18], gradual reductions in both energy intake and insulin daily dose are effective for gradually lowering fat mass without compromising muscle mass and safety. It should be noted that acute episodes of hypoglycaemia are associated with food cravings, which can cause disinhibited eating behaviours [92]. Training in settings of low circulating insulin levels should maximise energy provision and training adaptations without requiring excessive snacking, if weight loss is desired [63].

The female athlete Female athletes with type 1 diabetes may have unique glycaemic responses to training and competition depending on the stage of the menstrual cycle that they are currently in, and may have a reduced risk for hypoglycaemia as compared with male athletes [93]. Female athletes should be aware that insulin and carbohydrate needs before and after exercise/training may differ throughout their menstrual cycle. In general, higher blood glucose levels are found during the luteal phase, which is often not fully abolished by increasing

\section{b Competition}

Glucose range

Target

(\% of time)

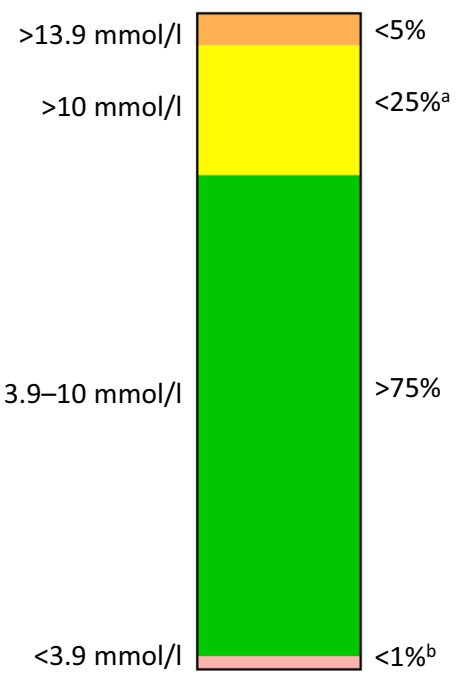

competition in individuals aged $<25$ years, if the $\mathrm{HbA}_{1 \mathrm{c}}$ goal is $<58 \mathrm{mmol} / \mathrm{mol}$ [7.5\%], then the TIR target should be set to $\sim 60 \%$ but a goal of $<4 \%$ time below target range $(<3.9 \mathrm{mmol} / 1$ glucose) should be maintained. ancludes percentage of values $>13.9 \mathrm{mmol} / 1$. ${ }^{\mathrm{b}}$ Includes percentage of values $<3.0 \mathrm{mmol} / \mathrm{l}$. This figure is available as part of a downloadable slideset

basal insulin delivery rate [94]. Since the luteal phase is also associated with high oestrogen levels and rising progesterone levels, hyperglycaemia is more prevalent [95] and an increased reliance on lipids as a fuel source during training and recovery may occur [96]. Moreover, the luteal phase is associated with less muscle glycogen mobilisation during endurance exercise, at least in those without diabetes [97], implying that less carbohydrate intake may be required for post-exercise glycogen replenishment.

Travel Regular travel, a key part of being a modern-day athlete, can present a significant challenge to athletes with type 1 diabetes. Individuals need to be well prepared for their journey by ensuring they have enough accessible supplies (Fig. 6) [98]. Difficulties may arise from practical decisions about packing insulin properly and bringing spare diabetesrelated supplies (e.g. meters, sensors, pumps, needles, glucagon, snacks, etc.) in carry-on luggage. Choosing appropriate travel insurance, dealing with airport security procedures, delayed flights and choosing appropriate on-board meals are also important considerations. When flying long distances and crossing multiple time zones, individuals must develop strategies to adapt to new time zones, limit the effects of jet lag/ travel on insulin needs and be hypervigilant to manage blood glucose levels [99]. Athletes should prepare for the possibility of losing diabetes-related supplies, consuming unfamiliar 


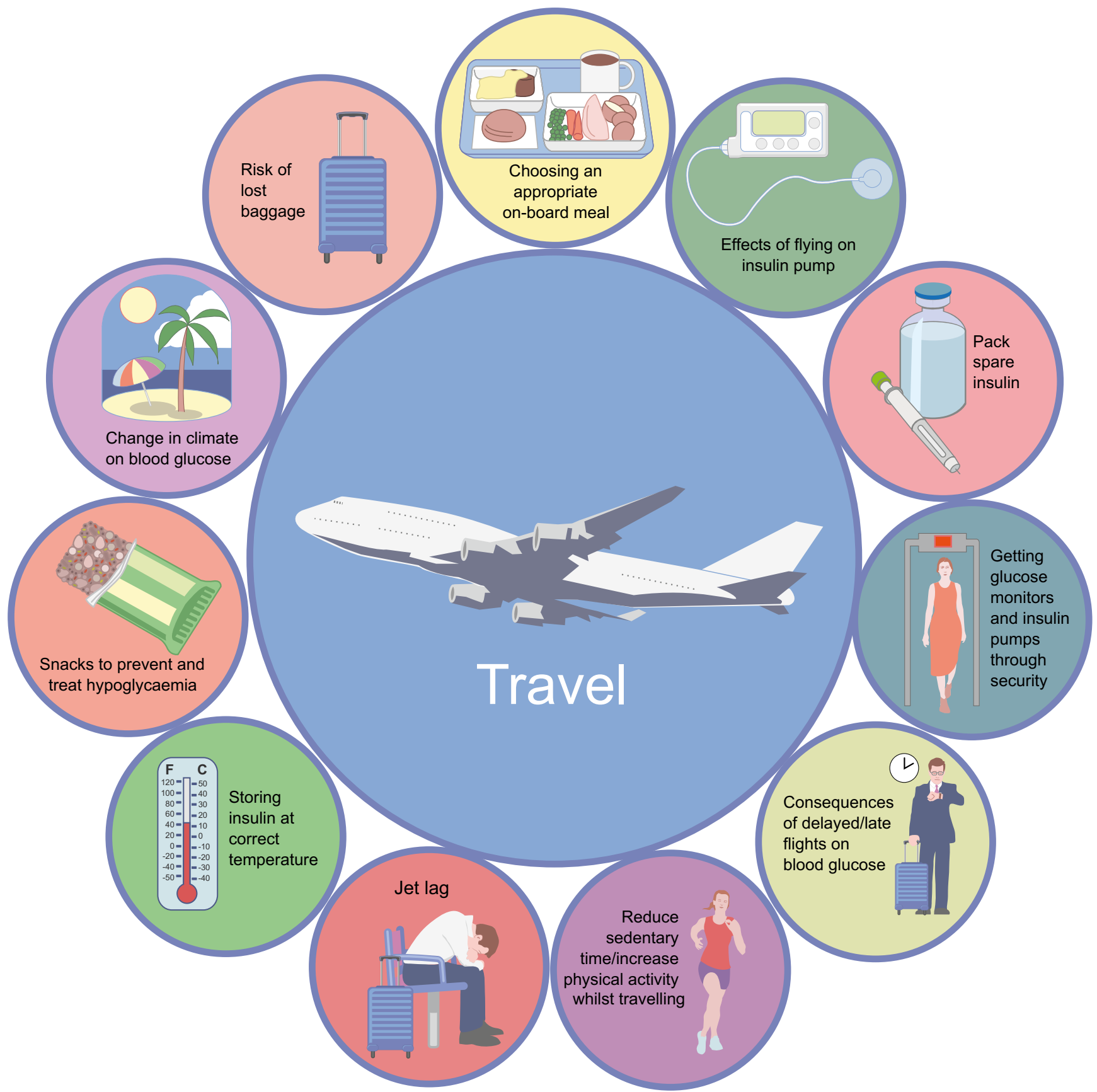

Fig. 6 Additional travel considerations for athletes with type 1 diabetes. A summary of practical considerations that an athlete with type 1 diabetes should take into account when travelling for athletic competition. Longdistance travel typically increases sedentary time (not shown), can alter food choices and tends to be associated with risk of hypo- and hyperglycaemia [99]. Increased vigilance around glucose monitoring and insulin-dose alterations, as well as access to healthy dietary options, diabetes supplies and, at least, light physical activity (not shown), should be considered. This figure is available as part of a downloadable slideset foods, and managing changes in climate and other environmental conditions. If significant time zone changes will occur, those using MDI may need to alter their basal insulin strategy, such as by splitting the basal dose into two doses spaced $\sim 12 \mathrm{~h}$ apart before departure [100], or use insulin degludec, which has a long half-life $(>25 \mathrm{~h})$ and is more flexible with respect to dose timing than insulin glargine ( $\sim 12 \mathrm{~h}$ half-life) [101].

\section{Summary}

Despite the challenges, athletes with type 1 diabetes continue to excel at all levels of competition, with some even achieving gold medals at the Olympic Games. Several strategies can be implemented to help manage athletes with type 1 diabetes (see Text box). Recent 
Recommendations for glycaemic management in competitive athletes with type 1 diabetes

\section{Considerations \\ prolonged exercise}

\section{Strategies} intensive exercise

\section{If using CSII:}

- $50-80 \%$ basal rate reduction set 90 min pre exercise

or

- Pump suspension at exercise onset (less effective at mitigating hypoglycaemia)

If using MDI:

- $20-50 \%$ basal rate reduction before exercise event and/or

- Carbohydrate consumption (up to $70-90 \mathrm{~g} / \mathrm{h}$ ) during exercise

All athletes:

- Mini-dose glucagon pre exercise (not currently approved)

\section{If using CSII:}

- Temporary insulin basal rate increase

If using MDI or CSII:

- Hydrate

- More prolonged aerobic warm-up

- Restructuring and overlearning of skills to offset stress

Glucose management with dynamic training

\section{If using rtCGM or isCGM:}

- Sugar-free hydration if glucose is elevated $(>10.0 \mathrm{mmol} / \mathrm{l})$

- Initiate carbohydrate feeding if glucose level drops below $8.0 \mathrm{mmol} / \mathrm{l}$ based on self-monitored blood glucose or CGM

- Review AGP with healthcare team

- Review current strategies for management around competition and training

- During training, aim for $>70 \%$ TIR, $<4 \%$ below $3.9 \mathrm{mmol} / \mathrm{l}$ and $<1 \%$ below $3.0 \mathrm{mmol} / \mathrm{l}$

- During competition, aim for $>75 \%$ TIR and $<1 \%$ below $3.9 \mathrm{mmol} / \mathrm{l}$

Glucose management with

If partaking in aerobic exercise:

different modalities and durations of exercise

\section{- Generally, causes drop in blood glucose levels}

If partaking in more intensive aerobic/anaerobic exercise:

- Generally, may cause rise in blood glucose in the fasted state and a rise in lactate

- Reductions in insulin not recommended

- Post-exercise hyperglycaemia can be managed with a conservative insulin bolus $(50 \%$ of usual correction dose)

Nutrition and carbohydrate intake

- Some athletes with type 1 diabetes claim to moderate carbohydrate intake to help with glucose management

- Training before breakfast is likely to require little-to-no carbohydrate ingestion during activity

- Carbohydrate loading pre exercise and/or feeding during competition is feasible as long as insulin is matched to the amount of carbohydrate

- If carbohydrate intake is limited following prolonged exercise, restoring muscle glycogen may take longer

If partaking in activities for 30-60 min:

- Under basal circulating insulin levels, 8-20 g carbohydrate will suffice

- With higher circulating insulin levels, 30-60 g/h carbohydrate may be needed

If partaking in activities for $>60 \mathrm{~min}$ :

- Likely to require carbohydrate intake and/or insulin reduction

- $\quad 0.4-1.3 \mathrm{~g}$ carbohydrate per $\mathrm{kg}$ of body mass per $\mathrm{h}$ recommended to prevent hypoglycaemia and enhance performance

Hydration

- Plain water or carbohydrate-electrolyte beverage should be consumed at a rate of $\sim 1 \mathrm{l} / \mathrm{h}$ based on performance goals and blood glucose level

rtCGM or isCGM

- Carbohydrate consumption should be initiated when interstitial glucose drops below $\sim 8.0$ $\mathrm{mmol} / \mathrm{l}$ during endurance events

- During training, aim for $>70 \% \mathrm{TIR},<4 \%$ below $3.9 \mathrm{mmol} / \mathrm{l}$, and $<1 \%$ below $3.0 \mathrm{mmol} / \mathrm{l}$

- During competition, aim for $>75 \%$ TIR 
advances in glucose monitoring technologies allow for minute by minute manipulations in insulin administration and nutrient intake to achieve near optimal glycaemic control. In general, athletes with type 1 diabetes perform training and competition with elevated circulating insulin levels and blunted glucagon responses that typically require a high rate of carbohydrate consumption in race events. However, some athletes follow a low-to-moderate-carbohydrate diet on non-race days, which appears to improve overall glycaemic control and preserve muscle glycogen storage capacity. Future research is needed to better define the optimal macronutrient diet for training and competition in these exceptional athletes. Maintaining a high TIR should allow for maximal performance and safety during periods of training, travel and competition.

Acknowledgements The authors would like to thank F. Fontana, Head of Performance at Team Novo Nordisk (Verona, Italy), for his input and edits to Fig. 1.

Authors' relationships and activities MCR has received lecture fees from Medtronic Diabetes, Novo Nordisk and Insulet, consulting/ advisory board fees from Xeris Pharmaceticles and Zucara therapeutics, research grants from Sanofi and Novo Nordisk and material funding from Dexcom. SNS is employed by Team Novo Nordisk Professional Cycling Team. OM has received lecture fees from Medtronic, travel grants from Novo Nordisk, Medtronic and Sanofi-Aventis, research grants from Sêr Cymru II COFUND fellowship/European Union and Novo Nordisk and material funding from Abbott Diabetes Care. JEY has received lecture fees from Dexcom and in-kind research support from Dexcom, Lifescan Canada and Abbott Nutrition. DPZ has received lecture fees from Medtronic Diabetes, Ascensia Diabetes and Insulet Corporation. PA has received unrestricted research grants from Novo Nordisk and has been part of advisory boards for Abbot, Eli Lilly, Novo Nordisk and Roche during the last 2 years. RMB reports having received honoraria, travel and educational grant support from Beneo, Boehringer-Ingelheim, Eli Lily and Company, Novo Nordisk and Sanofi-Aventis. PAF, SRC, IWG and CS declare that there are no relationships or activities that might bias, or be perceived to bias, their work.

Contribution statement All authors were responsible for drafting the article and revising it critically for important intellectual content. All authors approved the version to be published.

Open Access This article is licensed under a Creative Commons Attribution 4.0 International License, which permits use, sharing, adaptation, distribution and reproduction in any medium or format, as long as you give appropriate credit to the original author(s) and the source, provide a link to the Creative Commons licence, and indicate if changes were made. The images or other third party material in this article are included in the article's Creative Commons licence, unless indicated otherwise in a credit line to the material. If material is not included in the article's Creative Commons licence and your intended use is not permitted by statutory regulation or exceeds the permitted use, you will need to obtain permission directly from the copyright holder. To view a copy of this licence, visit http://creativecommons.org/licenses/by/4.0/.

\section{References}

1. Stadler M, Peric S, Strohner-Kaestenbauer H et al (2014) Mortality and incidence of renal replacement therapy in people with type 1 diabetes mellitus-a three decade long prospective observational study in the Lainz T1DM cohort. J Clin Endocrinol Metab 99(12):4523-4530. https://doi.org/10.1210/jc. 2014-2701

2. Foster NC, Beck RW, Miller KM et al (2019) State of type 1 diabetes management and outcomes from the T1D Exchange in 2016-2018. Diabetes Technol Ther 21(2):66-72. https://doi.org/ 10.1089/dia.2018.0384

3. Wu N, Bredin SSD, Guan Y et al (2019) Cardiovascular health benefits of exercise training in persons living with type 1 diabetes: a systematic review and meta-analysis. J Clin Med 8(2):253. https://doi.org/10.3390/jcm8020253

4. Moy CS, Songer TJ, LaPorte RE et al (1993) Insulin-dependent diabetes mellitus, physical activity, and death. Am J Epidemiol 137(1):74-81. https://doi.org/10.1093/oxfordjournals.aje. a116604

5. Sedivy P, Dezortova M, Drobny M, Vlasakova Z, Herynek V, Hajek M (2018) Differences in muscle metabolism in patients with type I diabetes - influence of gender and nephropathy studied by ${ }^{31} \mathrm{P}$ MR spectroscopy. Physiol Res 67(3):433-441. https://doi. org/10.33549/physiolres. 933745

6. Monaco CMF, Hughes MC, Ramos SV et al (2018) Altered mitochondrial bioenergetics and ultrastructure in the skeletal muscle of young adults with type 1 diabetes. Diabetologia 61(6):1411-1423. https://doi.org/10.1007/s00125-018-4602-6

7. Ruegsegger GN, Creo AL, Cortes TM, Dasari S, Nair KS (2018) Altered mitochondrial function in insulin-deficient and insulinresistant states. J Clin Invest 128(9):3671-3681. https://doi.org/ 10.1172/JCI120843

8. Murray B, Rosenbloom C (2018) Fundamentals of glycogen metabolism for coaches and athletes. Nutr Rev 76(4):243-259. https://doi.org/10.1093/nutrit/nuy001

9. Marliss EB, Vranic M (2002) Intense exercise has unique effects on both insulin release and its roles in glucoregulation: implications for diabetes. Diabetes 51(Suppl 1):S271-S283. https://doi. org/10.2337/diabetes.51.2007.s271

10. DuBose SN, Li Z, Sherr JL, Beck RW, Tamborlane WV, Shah VN (2020) Effect of exercise and meals on continuous glucose monitor data in healthy individuals without diabetes. J Diabetes Sci Technol. https://doi.org/10.1177/1932296820905904

11. Rothman DL, Magnusson I, Katz LD, Shulman RG, Shulman GI (1991) Quantitation of hepatic glycogenolysis and gluconeogenesis in fasting humans with ${ }^{13} \mathrm{C}$ NMR. Science 254(5031):573576. https://doi.org/10.1126/science.1948033

12. Buehler T, Bally L, Dokumaci AS, Stettler C, Boesch C (2016) Methodological and physiological test-retest reliability of ${ }^{13} \mathrm{C}$ MRS glycogen measurements in liver and in skeletal muscle of patients with type 1 diabetes and matched healthy controls. NMR Biomed 29(6):796-805. https://doi.org/10.1002/nbm.3531

13. Bischof MG, Bernroider E, Krssak M et al (2002) Hepatic glycogen metabolism in type 1 diabetes after long-term near normoglycemia. Diabetes 51(1):49-54. https://doi.org/10.2337/ diabetes.51.1.49

14. Hwang JH, Perseghin G, Rothman DL et al (1995) Impaired net hepatic glycogen synthesis in insulin-dependent diabetic subjects during mixed meal ingestion. A $13 \mathrm{C}$ nuclear magnetic resonance spectroscopy study. J Clin Invest 95(2):783-787. https://doi.org/ 10.1172/JCI117727 
15. Bischof MG, Krssak M, Krebs M et al (2001) Effects of short-term improvement of insulin treatment and glycemia on hepatic glycogen metabolism in type 1 diabetes. Diabetes 50(2):392-398

16. Riddell MC, Gallen IW, Smart CE et al (2017) Exercise management in type 1 diabetes: a consensus statement. Lancet Diabetes Endocrinol 5(5):377-390. https://doi.org/10.1016/S22138587(17)30014-1

17. Achten J, Jeukendrup AE (2004) Optimizing fat oxidation through exercise and diet. Nutrition 20(7-8):716-727. https://doi.org/10. 1016/j.nut.2004.04.005

18. Russell-Jones D, Khan R (2007) Insulin-associated weight gain in diabetes - causes, effects and coping strategies. Diabetes Obes Metab 9(6):799-812. https://doi.org/10.1111/j.1463-1326.2006. 00686.x

19. Ahola AJ, Forsblom C, Harjutsalo V, Groop P-H (2019) Dietary carbohydrate intake and cardio-metabolic risk factors in type 1 diabetes. Diabetes Res Clin Pract 155:107818. https://doi.org/10. 1016/j.diabres.2019.107818

20. Mosher PE, Nash MS, Perry AC, LaPerriere AR, Goldberg RB (1998) Aerobic circuit exercise training: effect on adolescents with well-controlled insulin-dependent diabetes mellitus. Arch Phys Med Rehabil 79(6):652-657

21. Wahrenberg H, Lönnqvist F, Engfeldt P, Arner P (1989) Abnormal action of catecholamines on lipolysis in adipocytes of type I diabetic patients treated with insulin. Diabetes 38(4):524 533. https://doi.org/10.2337/diab.38.4.524

22. Chokkalingam K, Tsintzas K, Norton L, Jewell K, Macdonald IA, Mansell PI (2007) Exercise under hyperinsulinaemic conditions increases whole-body glucose disposal without affecting muscle glycogen utilisation in type 1 diabetes. Diabetologia 50(2):414 421. https://doi.org/10.1007/s00125-006-0520-0

23. Rennie MJ, Bohé J, Smith K, Wackerhage H, Greenhaff P (2006) Branched-chain amino acids as fuels and anabolic signals in human muscle. J Nutr 136(1):264S-268S. https://doi.org/10. 1093/jn/136.1.264S

24. Wahren J, Hagenfeldt L, Felig P (1975) Splanchnic and leg exchange of glucose, amino acids, and free fatty acids during exercise in diabetes mellitus. J Clin Invest 55(6):1303-1314. https://doi.org/10.1172/JCI108050

25. O'Neill BT, Bhardwaj G, Penniman CM et al (2019) FoxO transcription factors are critical regulators of diabetes-related muscle atrophy. Diabetes 68(3):556-570. https://doi.org/10.2337/db180416

26. Petersen MC, Shulman GI (2018) Mechanisms of insulin action and insulin resistance. Physiol Rev 98(4):2133-2223. https://doi. org/10.1152/physrev.00063.2017

27. Aarnio P, Lauritsen T, Dela F (2001) Insulin secretion and glucose kinetics during exercise with and without pharmacological $\alpha_{1-}$ and $\alpha_{2}$-receptor blockade. Diabetes 50(8):1834-1843. https:// doi.org/10.2337/diabetes.50.8.1834

28. Koivisto VA, Felig P (1978) Effects of leg exercise on insulin absorption in diabetic patients. N Engl J Med 298(2):79-83. https://doi.org/10.1056/NEJM197801122980205

29. Peter R, Luzio SD, Dunseath G et al (2005) Effects of exercise on the absorption of insulin glargine in patients with type 1 diabetes. Diabetes Care 28(3):560-565

30. Berger M, Berchtold P, Cuppers HJ et al (1977) Metabolic and hormonal effects of muscular exercise in juvenile type diabetics. Diabetologia 13(4):355-365

31. Scott SN, Christiansen MP, Fontana FY et al (2020) Evaluation of factors related to glycemic management in professional cyclists with type 1 diabetes over a 7-day stage race. Diabetes Care 43(5):1142-1145. https://doi.org/10.2337/dc19-2302
32. Yardley JE, Iscoe KE, Sigal RJ, Kenny GP, Perkins BA, Riddell MC (2013) Insulin pump therapy is associated with less postexercise hyperglycemia than multiple daily injections: an observational study of physically active type 1 diabetes patients. Diabetes Technol Ther 15(1):84-88. https://doi.org/10.1089/dia. 2012.0168

33. Tagougui S, Taleb N, Molvau J, Nguyen É, Raffray M, RabasaLhoret R (2019) Artificial pancreas systems and physical activity in patients with type 1 diabetes: challenges, adopted approaches, and future perspectives. J Diabetes Sci Technol 13(6):1077-1090. https://doi.org/10.1177/1932296819869310

34. Seereiner S, Neeser K, Weber C et al (2010) Attitudes towards insulin pump therapy among adolescents and young people. Diabetes Technol Ther 12(1):89-94. https://doi.org/10.1089/dia. 2009.0080

35. Aronson R, Li A, Brown RE, McGaugh S, Riddell MC (2020) Flexible insulin therapy with a hybrid regimen of insulin degludec and continuous subcutaneous insulin infusion with pump suspension before exercise in physically active adults with type 1 diabetes (FIT Unthethered): a single-centre, open-label, proof-ofconcept, randomised crossover trial. Lancet Diabetes Endocrinol 8(6):511-523. https://doi.org/10.1016/S2213-8587(20)30114-5

36. Lucidi P, Porcellati F, Bolli GB, Fanelli CG (2018) Prevention and management of severe hypoglycemia and hypoglycemia unawareness: incorporating sensor technology. Curr Diab Rep 18(10):83

37. Moser O, Yardley JE, Bracken RM (2018) Interstitial glucose and physical exercise in type 1 diabetes: integrative physiology, technology, and the gap in-between. Nutrients 10(1):93. https://doi. org/10.3390/nu10010093

38. Moser O, Eckstein ML, McCarthy O et al (2019) Performance of the Freestyle Libre flash glucose monitoring (flash GM) system in individuals with type 1 diabetes: a secondary outcome analysis of a randomized crossover trial. Diabetes Obes Metab 21(11):25052512. https://doi.org/10.1111/dom.13835

39. Zaharieva DP, McGaugh S, Pooni R, Vienneau T, Ly T, Riddell MC (2019) Improved open-loop glucose control with basal insulin reduction 90 minutes before aerobic exercise in patients with type 1 diabetes on continuous subcutaneous insulin infusion. Diabetes Care 42(5):824-831. https://doi.org/10.2337/dc18-2204

40. Zaharieva DP, Cinar A, Yavelberg L, Jamnik V, Riddell MC (2019) No disadvantage to insulin pump off vs pump on during intermittent high-intensity exercise in adults with type 1 diabetes. Can J Diabetes 44(2):162-168. https://doi.org/10.1016/j.jcjd. 2019.05.015

41. Campbell MD, Walker M, Bracken RM et al (2015) Insulin therapy and dietary adjustments to normalize glycemia and prevent nocturnal hypoglycemia after evening exercise in type 1 diabetes: a randomized controlled trial. BMJ Open Diabetes Res Care 3(1): e000085. https://doi.org/10.1136/bmjdrc-2015-000085

42. Moser O, Eckstein ML, Mueller A et al (2019) Reduction in insulin degludec dosing for multiple exercise sessions improves time spent in euglycaemia in people with type 1 diabetes: a randomized crossover trial. Diabetes Obes Metab 21(2):349-356. https://doi. org/10.1111/dom.13534

43. Mattsson S, Jendle J, Adolfsson P (2019) Carbohydrate loading followed by high carbohydrate intake during prolonged physical exercise and its impact on glucose control in individuals with diabetes type 1-an exploratory study. Front Endocrinol 10:571. https://doi.org/10.3389/fendo.2019.00571

44. Mallad A, Hinshaw L, Schiavon M et al (2015) Exercise effects on postprandial glucose metabolism in type 1 diabetes: a triple-tracer approach. Am J Physiol Endocrinol Metab 308(12):E1106E1115. https://doi.org/10.1152/ajpendo.00014.2015 
45. Rickels MR, DuBose SN, Toschi E et al (2018) Mini-dose glucagon as a novel approach to prevent exercise-induced hypoglycemia in type 1 diabetes. Diabetes Care 41(9):1909-1916. https:// doi.org/10.2337/dc18-0051

46. Castle JR, El Youssef J, Wilson LM et al (2018) Randomized outpatient trial of single- and dual-hormone closed-loop systems that adapt to exercise using wearable sensors. Diabetes Care 41(7): 1471-1477. https://doi.org/10.2337/dc18-0228

47. Dizon S, Malcolm J, Rowan M, Keely EJ (2019) Patient perspectives on managing type 1 diabetes during high-performance exercise: what resources do they want? Diabetes Spectr 32(1):36-45. https://doi.org/10.2337/ds18-0016

48. Hanton S, Wadey R, Mellalieu SD (2008) Advanced psychological strategies and anxiety responses in sport. Sport Psychol 22(4): 472-490. https://doi.org/10.1123/tsp.22.4.472

49. Aronson R, Brown RE, Li A, Riddell MC (2019) Optimal insulin correction factor in post-high-intensity exercise hyperglycemia in adults with type 1 diabetes: the FIT study. Diabetes Care 42(1): 10-16. https://doi.org/10.2337/dc18-1475

50. Turner D, Luzio S, Gray BJ et al (2016) Algorithm that delivers an individualized rapid-acting insulin dose after morning resistance exercise counters post-exercise hyperglycaemia in people with type 1 diabetes. Diabet Med 33(4):506-510. https://doi.org/10. $1111 /$ dme. 12870

51. Yardley JE, Zaharieva DP, Jarvis C, Riddell MC (2015) The "ups" and "downs" of a bike race in people with type 1 diabetes: dramatic differences in strategies and blood glucose responses in the Paris-to-Ancaster Spring Classic. Can J Diabetes 39(2):105-110. https://doi.org/10.1016/j.jcjd.2014.09.003

52. Gallen IW, Hume C, Lumb A (2011) Fuelling the athlete with type 1 diabetes. Diabetes Obes Metab 13(2):130-136. https://doi.org/ 10.1111/j.1463-1326.2010.01319.x

53. Riddell MC, Pooni R, Yavelberg L et al (2019) Reproducibility in the cardiometabolic responses to high-intensity interval exercise in adults with type 1 diabetes. Diabetes Res Clin Pract 148:137-143. https://doi.org/10.1016/j.diabres.2019.01.003

54. De Pero R, Cibelli G, Cortis C, Sbriccoli P, Capranica L, Piacentini MF (2016) Stress related changes during TeamGym competition. J Sports Med Phys Fitness 56(5):639-647

55. Pinsker JE, Kraus A, Gianferante D et al (2016) Techniques for exercise preparation and management in adults with type 1 diabetes. Can J Diabetes 40(6):503-508. https://doi.org/10.1016/j.jcjd.2016.04.010

56. Al Khalifah RA, Suppère C, Haidar A, Rabasa-Lhoret R, Ladouceur M, Legault L (2016) Association of aerobic fitness level with exercise-induced hypoglycaemia in type 1 diabetes. Diabet Med 33(12):1686-1690. https://doi.org/10.1111/dme.13070

57. Fahey AJ, Paramalingam N, Davey RJ, Davis EA, Jones TW, Fournier PA (2012) The effect of a short sprint on postexercise whole-body glucose production and utilization rates in individuals with type 1 diabetes mellitus. J Clin Endocrinol Metab 97(11): 4193-4200. https://doi.org/10.1210/jc.2012-1604

58. Burke LM, Castell LM, Casa DJ et al (2019) International Association of Athletics Federations consensus statement 2019: nutrition for athletics. Int J Sport Nutr Exerc Metab 29(2):73-84. https://doi.org/10.1123/ijsnem.2019-0065

59. Brazeau AS, Mircescu H, Desjardins K et al (2013) Carbohydrate counting accuracy and blood glucose variability in adults with type 1 diabetes. Diabetes Res Clin Pract 99(1):19-23. https://doi. org/10.1016/j.diabres.2012.10.024

60. Sylow L, Kleinert M, Richter EA, Jensen TE (2017) Exercisestimulated glucose uptake - regulation and implications for glycaemic control. Nat Rev Endocrinol 13(3):133-148. https:// doi.org/10.1038/nrendo.2016.162
61. Brand-Miller J, Buyken AE (2012) The glycemic index issue. Curr Opin Lipidol 23(1):62-67. https://doi.org/10.1097/MOL. 0b013e32834ec705

62. Baldi JC, Cassuto NA, Foxx-Lupo WT, Wheatley CM, Snyder EM (2010) Glycemic status affects cardiopulmonary exercise response in athletes with type I diabetes. Med Sci Sports Exerc 42(8):1454-1459. https://doi.org/10.1249/MSS.0b013e3181d1fdb3

63. Scott SN, Anderson L, Morton JP, Wagenmakers AJM, Riddell MC (2019) Carbohydrate restriction in type 1 diabetes: a realistic therapy for improved glycaemic control and athletic performance? Nutrients 11(5):1022. https://doi.org/10.3390/nu1 1051022

64. McKewen MW, Rehrer NJ, Cox C, Mann J (1999) Glycaemic control, muscle glycogen and exercise performance in IDDM athletes on diets of varying carbohydrate content. Int J Sports Med 20(6):349-353. https://doi.org/10.1055/s-2007-971143

65. Jensen J, Rustad PI, Kolnes AJ, Lai Y-C (2011) The role of skeletal muscle glycogen breakdown for regulation of insulin sensitivity by exercise. Front Physiol 2:112. https://doi.org/10.3389/ fphys.2011.00112

66. Alghannam AF, Gonzalez JT, Betts JA (2018) Restoration of muscle glycogen and functional capacity: role of post-exercise carbohydrate and protein co-ingestion. Nutrients 10(2):253. https://doi.org/10.3390/nu10020253

67. Jentjens RL, van Loon LJ, Mann CH, Wagenmakers AJ, Jeukendrup AE (2001) Addition of protein and amino acids to carbohydrates does not enhance postexercise muscle glycogen synthesis. J Appl Physiol 91(2):839-846. https://doi.org/10. 1152/jappl.2001.91.2.839

68. Gomez AM, Gomez C, Aschner P et al (2015) Effects of performing morning versus afternoon exercise on glycemic control and hypoglycemia frequency in type 1 diabetes patients on sensor-augmented insulin pump therapy. J Diabetes Sci Technol 9(3):619-624. https://doi.org/10.1177/ 1932296814566233

69. Turner D, Luzio S, Gray BJ et al (2015) Impact of single and multiple sets of resistance exercise in type 1 diabetes. Scand J Med Sci Sports 25(1):e99-e109. https://doi.org/10.1111/sms.12202

70. Riddell MC, Milliken J (2011) Preventing exercise-induced hypoglycemia in type 1 diabetes using real-time continuous glucose monitoring and a new carbohydrate intake algorithm: an observational field study. Diabetes Technol Ther 13(8):819-825. https:// doi.org/10.1089/dia.2011.0052

71. Francescato MP, Stel G, Stenner E, Geat M (2015) Prolonged exercise in type 1 diabetes: performance of a customizable algorithm to estimate the carbohydrate supplements to minimize glycemic imbalances. PLoS One 10(4):e0125220. https://doi.org/ 10.1371/journal.pone.0125220

72. Murillo S, Brugnara L, Novials A (2010) One year follow-up in a group of half-marathon runners with type-1 diabetes treated with insulin analogues. J Sports Med Phys Fitness 50(4):506-510

73. McCarthy O, Eckstein ML, Scott SN et al (2020) Glycemic responses to strenuous training in male professional cyclists with type 1 diabetes: a prospective observational study. BMJ Open Diabetes Res Care 8(1): e001245. https://doi.org/10.1136/bmjdrc-2020-001245

74. Sane T, Helve E, Pelkonen R, Koivisto VA (1988) The adjustment of diet and insulin dose during long-term endurance exercise in type 1 (insulin-dependent) diabetic men. Diabetologia 31(1):3540. https://doi.org/10.1007/bf00279130

75. van Dijk J-W, Eijsvogels TM, Nyakayiru J et al (2016) Glycemic control during consecutive days with prolonged walking exercise in individuals with type 1 diabetes mellitus. Diabetes Res Clin Pract 117:74-81. https://doi.org/10.1016/j.diabres.2016.04.053 
76. Gawrecki A, Zozulinska-Ziolkiewicz D, Matejko B, Hohendorff J, Malecki MT, Klupa T (2018) Safe completion of a trail running ultramarathon by four men with type 1 diabetes. Diabetes Technol Ther 20(2):147-152. https://doi.org/10.1089/dia.2017.0296

77. APA (2016) Nutrition and athletic performance. Med Sci Sports Exerc 48(3):543-568. https://doi.org/10.1249/MSS. 0000000000000852

78. Buoite Stella A, Yardley J, Francescato MP, Morrison SA (2018) Fluid intake habits in type 1 diabetes individuals during typical training bouts. Ann Nutr Metab 73(1):10-18. https://doi.org/10. $1159 / 000489823$

79. Yardley JE, Colberg SR (2017) Update on management of type 1 diabetes and type 2 diabetes in athletes. Curr Sports Med Rep 16(1):38-44. https://doi.org/10.1249/JSR.0000000000000327

80. Adolfsson P, Hartvig NV, Kaas A, Møller JB, Hellman J (2020) Increased time in range and improved insulin adherence after introduction of a smart connected insulin pen. Diabetes Technol Ther. https://doi.org/10.1089/dia.2019.0411

81. Tagougui S, Taleb N, Rabasa-Lhoret R (2019) The benefits and limits of technological advances in glucose management around physical activity in patients type 1 diabetes. Front Endocrinol 9: 818. https://doi.org/10.3389/fendo.2018.00818

82. Kruger DF, Edelman SV, Hinnen DA, Parkin CG (2019) Reference guide for integrating continuous glucose monitoring into clinical practice. Diabetes Educ 45(1_suppl):3S-20S. https://doi.org/10.1177/0145721718818066

83. Battelino T, Danne T, Bergenstal RM et al (2019) Clinical targets for continuous glucose monitoring data interpretation: recommendations from the International Consensus on Time in Range. Diabetes Care 42(8):1593-1603. https://doi.org/10.2337/dci19-0028

84. Koivikko ML, Tulppo MP, Kiviniemi AM et al (2012) Autonomic cardiac regulation during spontaneous nocturnal hypoglycemia in patients with type 1 diabetes. Diabetes Care 35(7):1585-1590. https://doi.org/10.2337/dc11-2120

85. Monnier L, Colette C, Wojtusciszyn A et al (2017) Toward defining the threshold between low and high glucose variability in diabetes. Diabetes Care 40(7):832-838. https://doi.org/10.2337/ dc16-1769

86. Gold AE, MacLeod KM, Frier BM (1994) Frequency of severe hypoglycemia in patients with type I diabetes with impaired awareness of hypoglycemia. Diabetes Care 17(7):697-703. https://oi.org/10.2337/diacare.17.7.697

87. Sandoval DA, Guy DLA, Richardson MA, Ertl AC, Davis SN (2004) Effects of low and moderate antecedent exercise on counterregulatory responses to subsequent hypoglycemia in type 1 diabetes. Diabetes 53(7):1798-1806

88. Farrell CM, McNeilly AD, Fournier P et al (2020) A randomised controlled study of high intensity exercise as a dishabituating stimulus to improve hypoglycaemia awareness in people with type 1 diabetes: a proof-of-concept study. Diabetologia 63(4):853-863. https://doi.org/10.1007/s00125-019-05076-5

89. Reale R, Slater G, Burke LM (2017) Acute-weight-loss strategies for combat sports and applications to Olympic success. Int J Sports Physiol Perform 12(2):142-151. https://doi.org/10.1123/ijspp. 2016-0211

90. Reale R, Slater G, Burke LM (2017) Individualised dietary strategies for Olympic combat sports: acute weight loss, recovery and competition nutrition. Eur J Sport Sci 17(6):727-740. https://doi. org/10.1080/17461391.2017.1297489

91. Matthews JJ, Stanhope EN, Godwin MS, Holmes MEJ, Artioli GG (2019) The magnitude of rapid weight loss and rapid weight gain in combat sport athletes preparing for competition: a systematic review. Int J Sport Nutr Exerc Metab 29(4):441-452. https://doi.org/10.1123/ijsnem.2018-0165

92. Strachan MWJ, Ewing FME, Frier BM, Harper A, Deary IJ (2004) Food cravings during acute hypoglycaemia in adults with type 1 diabetes. Physiol Behav 80(5):675-682. https://doi.org/10.1016/j. physbeh.2003.12.003

93. Brockman NK, Sigal RJ, Kenny GP, Riddell MC, Perkins BA, Yardley JE (2019) Sex-related differences in blood glucose responses to resistance exercise in adults with type 1 diabetes: a secondary data analysis. Can J Diabetes 44(3):267-273. https:// doi.org/10.1016/j.jcjd.2019.08.006

94. Lunt H, Brown LJ (1996) Self-reported changes in capillary glucose and insulin requirements during the menstrual cycle. Diabet Med 13(6):525-530. https://doi.org/10.1002/(SICI)10969136(199606)13:6<525::AID-DIA123>3.0.CO;2-D

95. Brown SA, Jiang B, McElwee-Malloy M, Wakeman C, Breton MD (2015) Fluctuations of hyperglycemia and insulin sensitivity are linked to menstrual cycle phases in women with T1D. J Diabetes Sci Technol 9(6):1192-1199. https://doi.org/10.1177/ 1932296815608400

96. Riddell MC, Partington SL, Stupka N, Armstrong D, Rennie C, Tarnopolsky MA (2003) Substrate utilization during exercise performed with and without glucose ingestion in female and male endurance trained athletes. Int J Sport Nutr Exerc Metab 13(4): 407-421. https://doi.org/10.1123/ijsnem.13.4.407

97. Devries MC, Hamadeh MJ, Phillips SM, Tarnopolsky MA (2006) Menstrual cycle phase and sex influence muscle glycogen utilization and glucose turnover during moderate-intensity endurance exercise. Am J Physiol Regul Integr Comp Physiol 291(4): R1120-R1128. https://doi.org/10.1152/ajpregu.00700.2005

98. Burnett JCD (2006) Long- and short-haul travel by air: issues for people with diabetes on insulin. J Travel Med 13(5):255-260. https://doi.org/10.1111/j.1708-8305.2006.00057.x

99. Pinsker JE, Schoenberg BE, Garey C, Runion A, Larez A, Kerr D (2017) Perspectives on long-distance air travel with type 1 diabetes. Diabetes Technol Ther 19(12):744-748. https://doi.org/10. 1089/dia.2017.0259

100. Garg SK, Gottlieb PA, Hisatomi ME et al (2004) Improved glycemic control without an increase in severe hypoglycemic episodes in intensively treated patients with type 1 diabetes receiving morning, evening, or split dose insulin glargine. Diabetes Res Clin Pract 66(1):49-56. https://doi.org/10.1016/j.diabres.2004.02.008

101. Haahr H, Heise T (2014) A review of the pharmacological properties of insulin degludec and their clinical relevance. Clin Pharmacokinet 53(9):787-800. https://doi.org/10.1007/s40262-014-0165-y

102. Coyle EF, Coggan AR, Hemmert MK, Ivy JL (1986) Muscle glycogen utilization during prolonged strenuous exercise when fed carbohydrate. J Appl Physiol 61(1):165-172. https://doi.org/ 10.1152/jappl.1986.61.1.165

103. Rowlands DS, Hopkins WG (2002) Effects of high-fat and highcarbohydrate diets on metabolism and performance in cycling. Metab Clin Exp 51(6):678-690. https://doi.org/10.1053/meta.2002. 32723

104. Bracken RM, Gray BJ, Turner D (2014) Comparison of the metabolic responses to ingestion of hydrothermally processed highamylopectin content maize, uncooked maize starch or dextrose in healthy individuals. Br J Nutr 111(7):1231-1238. https://doi. org/10.1017/S0007114513003619

105. Campbell MD, Walker M, Trenell MI et al (2014) A low-glycemic index meal and bedtime snack prevents postprandial hyperglycemia and associated rises in inflammatory markers, providing protection from early but not late nocturnal hypoglycemia 
following evening exercise in type 1 diabetes. Diabetes Care 37(7):1845-1853. https://doi.org/10.2337/dc14-0186

106. Campbell MD, Walker M, Trenell MI et al (2013) Large pre- and postexercise rapid-acting insulin reductions preserve glycemia and prevent early- but not late-onset hypoglycemia in patients with type 1 diabetes. Diabetes Care 36(8):2217-2224. https://doi.org/10.2337/ dc12-2467

107. Campbell MD, Walker M, Trenell MI et al (2014) Metabolic implications when employing heavy pre- and post-exercise rapid-acting insulin reductions to prevent hypoglycaemia in type 1 diabetes patients: a randomised clinical trial. PLoS One 9(5): e97143. https://doi.org/10.1371/journal.pone.0097143
108. West DJ, Morton RD, Bain SC, Stephens JW, Bracken RM (2010) Blood glucose responses to reductions in pre-exercise rapid-acting insulin for $24 \mathrm{~h}$ after running in individuals with type 1 diabetes. $\mathrm{J}$ Sports Sci 28(7):781-788. https://doi.org/10.1080/ 02640411003734093

109. Manore MM (2005) Exercise and the Institute of Medicine recommendations for nutrition. Curr Sports Med Rep 4(4):193-198. https://doi.org/10.1097/01.csmr.0000306206.72186.00

Publisher's note Springer Nature remains neutral with regard to jurisdictional claims in published maps and institutional affiliations. 